\title{
BMJ Open Mobilising cross-sector collaborations to improve population health in US rural communities: a qualitative study
}

\author{
Xi Zhu, ${ }^{1}$ Paula Weigel, ${ }^{1}$ Jure Baloh, ${ }^{2}$ Mochamad Nataliansyah, ${ }^{1}$ Nichole Gunn, ${ }^{1}$ \\ Keith Mueller ${ }^{1}$
}

To cite: Zhu X, Weigel P, Baloh J, et al. Mobilising cross-sector collaborations to improve population health in US rural communities: a qualitative study. BMJ Open 2019;9:e030983. doi:10.1136/ bmjopen-2019-030983

- Prepublication history for this paper is available online. To view these files, please visit the journal online (http://dx.doi. org/10.1136/bmjopen-2019030983).

Received 10 April 2019 Revised 09 September 2019 Accepted 16 October 2019

Check for updates

(C) Author(s) (or their employer(s)) 2019. Re-use permitted under CC BY-NC. No commercial re-use. See rights and permissions. Published by BMJ.

${ }^{1}$ College of Public Health, Department of Health Management and Policy, University of lowa, lowa City, lowa, USA

${ }^{2}$ Department of Health Policy and Management, University of Arkansas for Medical Sciences, Little Rock, Arkansas, USA

Correspondence to

Professor Xi Zhu;

xi-zhu@uiowa.edu

\section{ABSTRACT}

Objectives This study examines types and forms of crosssector collaborations employed by rural communities to address community health issues and identifies factors facilitating or inhibiting such collaborations.

Setting We conducted case studies of four rural communities in the US state of lowa that have demonstrated progress in creating healthier communities. Participants Key informants from local public health departments, hospitals and other health-promoting organisations and groups participated in this study. Twenty-two key-informant interviews were conducted. Participants were selected based on their organisation's involvement in community health initiatives.

Results Rural communities used different forms of collaborations, including cross-sector partnership, crosssector interaction and cross-sector exploration, to address community health issues. Stakeholders from public health, healthcare, social services, education and business sectors were involved. Factors facilitating cross-sector collaborations include health-promoting local contexts, seed initiatives that mobilise communities, hospital visions that embrace broad views of health and shared collaboration leadership and governance. Challenges to developing and sustaining cross-sector collaborations include different institutional logics, financial and human resources constraints and geographic dispersion.

Conclusions Rural communities use cross-sector collaborations to address community health issues in the forms of interaction and exploration, but real and lasting partnerships are rare. The development, operation and sustainment of cross-sector collaborations are influenced by a set of contextual and practical factors. Practical strategies and policy interventions may be used to enhance cross-sector collaborations in rural communities.

\section{INTRODUCTION}

There is long-standing recognition that where people live greatly influences their chances of being healthy. Schools, workplaces, neighbourhoods and the broader community influence the values that people place on health and their opportunities to make healthy choices. ${ }^{1-3}$ Accumulating evidence supports that upstream social factors (eg, educational attainment, income and occupation) have wide-ranging effects on health across the

\section{Strengths and limitations of this study}

This is the first study to examine cross-sector collaborations employed by US rural communities to improve population health, focusing on rural-specific practices, facilitators and challenges.

- This study uses an explanatory sequential design and multiple data sources including County Health Rankings, community health needs assessments, interviews and archives to develop an in-depth understanding of the issue.

- The use of qualitative methods and a small number of cases limits our ability to generalise our findings.

- We only selected rural communities that demonstrated progress towards creating healthy communities and did not include communities lagging in such progress in our study. Thus, the findings may be particular to those similar to the selected communities.

life course by shaping daily living conditions and influencing downstream determinants of health including health behaviours. ${ }^{4-6}$ Therefore, addressing social determinants of health is critical for any systematic effort aiming to improve population health and health equity. ${ }^{3}$ Building on such evidence and a vision to build a Culture of Health in the USA, the Robert Wood Johnson Foundation (RWJF) developed a framework highlighting four action areas that include making health a shared value, fostering cross-sector collaboration, creating healthier, more equitable communities and strengthening integration of health systems and services. ${ }^{78}$

The focus on fostering cross-sector collaborations to improve well-being reflects a confluence of several motives. First, health is more than the absence of disease and medical care alone cannot improve health without addressing social determinants of health. Second, while the health sectors (eg, healthcare and public health) play a key role in promoting health, they cannot address many social conditions that affect health and health 
behaviours (eg, access to healthy food, affordable housing and safe environment) by themselves. Cross-sector collaborations have the potential to align resources and contributions of multiple sectors to address these issues. Third, there are numerous examples of cross-sector collaboration that have successfully improved health and wellbeing at organisational or community level. ${ }^{9}$

The use of cross-sector collaborations to address public issues has gained increasing acceptance in recent years. ${ }^{10}{ }^{11}$ In the public administration literature, crosssector collaboration refers to 'the linking or sharing of information, resources, activities and capabilities by organizations in two or more sectors to achieve jointly an outcome that could not be achieved by organizations in one sector separately'. ${ }^{12}$ Previous studies documented that cross-sector collaboration has been employed in efforts to prevent infectious diseases, address obesity and non-communicable diseases, promote healthy eating and active living, improve early child care and education and advance health-promoting policy. ${ }^{11}{ }^{13} 14$ Research showed that urban communities that engaged a broad array of sectors in population health activities gained sizeable improvement in health outcomes measured as decline in deaths due to preventable causes, including cardiovascular disease, diabetes and influenza. ${ }^{15}$ However, our understanding of cross-sector collaborations and their impact draws largely on the experience of urban communities. There is a dearth of research examining the types and forms of cross-sector collaborations employed by rural communities to address community health issues.

To address this knowledge gap, we conducted a multisite case study of four rural communities in a Midwest state in the USA that have demonstrated progress in engaging stakeholders from multiple sectors to create healthier communities. We analysed interview and archival data to examine the types and forms of cross-sector collaborations in these communities and factors facilitating or inhibiting collaborations.

\section{METHODS}

This study used an explanatory sequential design in which County Health Rankings ${ }^{16}$ and other secondary data were analysed to guide case selection, data collection and analysis. ${ }^{17}$ We focused on rural communities in a Midwest state of the USA to leverage our knowledge of the community contexts and policies that might influence cross-sector practices. The study was approved by the Institutional Review Board of the University of Iowa.

\section{Case selection}

We selected cases based on two criteria. First, we used County Health Rankings to identify rural counties that either have consistently ranked among the top quartile or have shown significant improvement in their rankings between 2010 and 2016. Based on US Department of Agriculture's definitions, counties with an Urban Influence Code higher than two (ie, non-metropolitan counties) were considered as rural counties. ${ }^{18}$ The County Health Rankings rank counties or county equivalents within each state using over 30 population-health indicators that are standardised, weighted and summed to measure health outcomes and health factors. Second, we reviewed community health needs assessments and health improvement plans from county health departments and hospitals to evaluate whether a broad definition of health (ie, including well-being, quality of life and social determinants of health) and cross-sector approaches for improving health (ie, including non-health partners) were evident in these documents.

\section{Patient and public involvement}

No patient was involved.

\section{Data collection}

We used RWJF's Culture of Health Action Framework to develop an interview guide. The interview guide included questions related to local activities and experiences in the four action areas, including cross-sector collaborations to improve well-being, integration of health services, promoting health as a shared value and addressing health equity. We conducted 22 semistructured interviews (19 individual and 3 group interviews) with key informants during site visits to the communities. We identified interviewees through a snowball sampling process in which the hospital and public health leaders served as our initial subjects. The interviews represented perspectives of local hospitals, public health departments and other healthpromoting organisations and groups. All interviews were recorded and transcribed after obtaining interviewees' verbal consent. This study was exempted from written consent requirements because it did not involve collection of personal information or physical interactions with the participants. We collected additional archival data on relevant cross-sector programmes and initiatives based on the interviews, which included webpages, newsletters, reports and publications.

\section{Analysis}

We developed a coding template based on the Culture of Health Action Framework and preliminary themes identified during site visits. The coding template included the following a priori codes related to cross-sector collaborations: (1) the type and focus of the collaboration; (2) organisations involved and their roles; (3) coordination between organisations; (4) facilitators for collaboration; (5) barriers to collaboration and (6) salient contextual or historical factors.

Two members of the research team read the transcripts and archival data and independently coded relevant segments into the coding template. Emergent codes were used for coding relevant information that did not fall into the prescribed codes. For this analysis, a pertinent emergent code concerned the perceived impact of cross-sector collaborations. Coding team meetings were held to refine the coding template and ensure intercoder reliability. ${ }^{19}$ 
Table 1 Community profile

\begin{tabular}{|c|c|c|c|c|}
\hline & Community D & Community G & Community I & Community W \\
\hline \multicolumn{5}{|l|}{ Demographics } \\
\hline Population & 21000 & 12000 & 21000 & 25000 \\
\hline Age $\geq 65$ & $17.7 \%$ & $19.4 \%$ & $16.2 \%$ & $18.0 \%$ \\
\hline White & $96.7 \%$ & $98.3 \%$ & $97.7 \%$ & $96.7 \%$ \\
\hline $\begin{array}{l}\text { Median household } \\
\text { income }\end{array}$ & $\$ 54000$ & $\$ 57000$ & $\$ 56000$ & $\$ 62000$ \\
\hline Median property value & $\$ 158000$ & $\$ 126000$ & $\$ 127000$ & $\$ 152000$ \\
\hline In poverty & $8.1 \%$ & $6.2 \%$ & $9.5 \%$ & $8.3 \%$ \\
\hline Uninsured & $5.1 \%$ & $4.3 \%$ & $9.1 \%$ & $3.7 \%$ \\
\hline \multicolumn{5}{|l|}{ County Health Rankings } \\
\hline Health factors & Maintained high rank & Maintained high rank & $\begin{array}{l}\text { Improved rank from } \\
60-65 \text { to } 40-45\end{array}$ & Maintained high rank \\
\hline Health outcomes & Maintained high rank & $\begin{array}{l}\text { Improved rank from } \\
25-30 \text { to } 5-10\end{array}$ & $\begin{array}{l}\text { Improved rank from } \\
45-50 \text { to } 20-25\end{array}$ & Maintained high rank \\
\hline \multicolumn{5}{|l|}{ Health needs and priorities } \\
\hline Priority areas & $\begin{array}{l}\text { Mental and } \\
\text { behavioural health } \\
\text { Healthy behaviours } \\
\text { Active living } \\
\text { Prevention and } \\
\text { management of chronic } \\
\text { diseases }\end{array}$ & $\begin{array}{l}\text { Access to } \\
\text { healthcare services } \\
\text { Chronic disease } \\
\text { management } \\
\text { Disease prevention } \\
\text { and wellness }\end{array}$ & $\begin{array}{l}\text { Healthy behaviours } \\
\text { Substance abuse } \\
\text { Chronic disease } \\
\text { management }\end{array}$ & $\begin{array}{l}\text { Chronic disease } \\
\text { management } \\
\text { Cancer prevention } \\
\text { and treatment } \\
\text { Wellness services } \\
\text { Access to mental } \\
\text { health services } \\
\quad \text { Substance abuse }\end{array}$ \\
\hline
\end{tabular}

Four investigators independently reviewed the coded data to identify themes. First, we categorised each cross-sector collaboration's type by the health issues it addressed and the form of collaboration by its organising and governance structure. Second, we identified common factors across cases that facilitated or inhibited cross-sector collaborations in the rural communities. Third, we derived themes that interviewees used to explain the impact of cross-sector collaborations on community health and culture. The team discussed the definitions and significance of the identified themes until we reached agreement. ${ }^{20}$

\section{RESULTS}

Key characteristics of the four communities are summarised in table 1 . At the county level, total populations range from 12000 to 25000 and are greater than $96 \%$ white. Poverty rates range between $6.2 \%$ and $9.5 \%$. Uninsured rates in these counties range between $3.7 \%$ and $9.1 \%$. More than $50 \%$ of all employment in the counties are in four major categories: educational services, manufacturing, healthcare and social assistance and retail trade. Two of the four communities are home to small liberal arts colleges.

\section{Types and forms of cross-sector collaborations}

We identified 49 collaborative initiatives in these rural communities, which addressed five common types of health issues: physical activity and fitness, nutrition and healthy food access, outdoor environment, public and occupational safety and healthcare access. Table 2 summarises the types and forms of cross-sector initiatives the four communities used to promote health and the collaborators involved in these initiatives. Various organisations and individuals were involved, representing both health and non-health sectors. These included hospitals, public health departments, businesses, K-12 schools, higher education, local government, faith organisations, charity organisations and community activists. A statewide cooperative extension from a land-grant university had local offices in two communities and was active in healthrelated collaborations.

Three unique collaboration forms emerged from our analysis: cross-sector partnership, cross-sector interaction and cross-sector exploration. Cross-sector partnership refers 
Table 2 Types and forms of cross-sector collaborations for improving population health

\begin{tabular}{|c|c|c|c|c|}
\hline & Community D & Community G & Community I & Community W \\
\hline $\begin{array}{l}\text { Physical activity } \\
\text { and fitness }\end{array}$ & $\begin{array}{l}\text { Sectors involved: } \\
\text { community activist, } \\
\text { public health } \\
\text { Form: cross-sector } \\
\text { interaction }\end{array}$ & $\begin{array}{l}\text { Sectors involved: } \\
\text { hospital, fitness facility, } \\
\text { faith organisation, } \\
\text { cooperative extension, } \\
\text { local government, K-12 } \\
\text { school } \\
\text { Form: cross-sector } \\
\text { partnership }\end{array}$ & $\begin{array}{l}\text { Sectors involved: hospital } \\
\text { Form: cross-sector } \\
\text { exploration }\end{array}$ & $\begin{array}{l}\text { Sectors involved: } \\
\text { hospital, business, K-12 } \\
\text { school, fitness facility } \\
\text { Form: cross-sector } \\
\text { interaction }\end{array}$ \\
\hline $\begin{array}{l}\text { Nutrition and } \\
\text { healthy food } \\
\text { access }\end{array}$ & $\begin{array}{l}\text { Sectors involved: } \\
\text { community activist, K-12 } \\
\text { school, higher education } \\
\text { Form: cross-sector } \\
\text { partnership }\end{array}$ & $\begin{array}{l}\text { Sectors involved: } \\
\text { hospital, K-12 school, } \\
\text { fitness facility } \\
\text { Form: cross-sector } \\
\text { interaction }\end{array}$ & $\begin{array}{l}\text { Sectors involved: hospital, } \\
\text { business, K-12 school, } \\
\text { local government, faith } \\
\text { organisation, cooperative } \\
\text { extension } \\
\text { Form: cross-sector interaction }\end{array}$ & $\begin{array}{l}\text { Sectors involved: } \\
\text { hospital, K-12 school } \\
\text { Form: cross-sector } \\
\text { interaction }\end{array}$ \\
\hline $\begin{array}{l}\text { Public and } \\
\text { occupational } \\
\text { safety }\end{array}$ & & & $\begin{array}{l}\text { Sectors involved: cooperative } \\
\text { extension, K-12 school } \\
\text { Form: cross-sector interaction }\end{array}$ & $\begin{array}{l}\text { Sectors involved: } \\
\text { hospital, business } \\
\text { Form: cross-sector } \\
\text { exploration }\end{array}$ \\
\hline Healthcare access & $\begin{array}{l}\text { Sectors involved: } \\
\text { hospital, local } \\
\text { government } \\
\text { Form: cross-sector } \\
\text { interaction }\end{array}$ & & $\begin{array}{l}\text { Sectors involved: hospital, } \\
\text { business, faith organisation, } \\
\text { cooperative extension, K-12 } \\
\text { school, local government } \\
\text { Form: cross-sector interaction }\end{array}$ & $\begin{array}{l}\text { Sectors involved: } \\
\text { hospital, K-12 school, } \\
\text { charity organisation } \\
\text { Form: cross-sector } \\
\text { interaction }\end{array}$ \\
\hline
\end{tabular}

to collaborations in which all participants were fully and equally engaged. Participants could clearly describe a shared leadership and governance structure, and they emphasised joint mission, intense interaction, shared decision-making and collective impact as organising principles. Cross-sector interaction refers to collaborations in which one participant played a leading role with limited or infrequent interactions with other participants. There was no clear evidence of formal governance structure or shared decision-making. An example of a cross-sector interaction is local hospitals sponsoring nutrition education programmes at local schools. Cross-sector exploration refers to organisations working across sectoral boundaries and investing in activities not within their traditional scope of work. One hospital, for example, invested in and operated the only fitness centre in the community. We labelled this form of collaboration cross-sector exploration because there typically was minimum involvement from other collaborators.

\section{Factors facilitating cross-sector collaborations}

We identified four facilitating factors for mobilising crosssector collaborations in rural communities (see table 3).

Health-promoting context: Interviewees from three communities stated that their communities have historically had a strong and visible culture valuing health and well-being. In the fourth community, interviewees described people's views and expectations about health as rapidly improving. Community members recognised the role of local hospitals, activists and small colleges in fostering health-promoting cultures. Outdoor environment was another contributing factor in one of the communities. Interviewees stated that having a healthpromoting context attracted people with similar mindsets to move into the area, which consequently resulted in a stronger sense of community and health consciousness. Such community context facilitated further communitywide dialogue, activism and collaborations for improving health.

Seed initiative: The lasting impact of seed initiatives was evident in all four communities. One community started a Food and Fitness Initiative for children with the support of a foundation grant. Community activists formed work groups to create policies and practices supporting healthy eating and active living for children, families and community members. The initiative continued to build partnerships with local schools, businesses, government agencies, colleges and foundations to sustain its programmes for more than 7 years. 
Table 3 Factors facilitating and inhibiting cross-sector collaborations in rural communities

\section{Facilitating factors}

Healthpromoting context

Seed initiative

$\begin{array}{ll}\text { Hospital vision } & \begin{array}{l}\text { Expands hospital's role; transforms } \\ \text { mindsets; creates a hub for improving } \\ \text { health and well-being; provides resources }\end{array} \\ \begin{array}{ll}\text { Cross-sector } & \text { Creates and updates shared aims; } \\ \text { leadership and } & \begin{array}{l}\text { coordinates resources and actions; } \\ \text { governance }\end{array} \\ \text { reduces redundancy and competition; } \\ \text { facilitates communication and trust }\end{array}\end{array}$

\begin{tabular}{ll}
\hline Inhibiting factors & Impact \\
\hline $\begin{array}{l}\text { Different } \\
\text { institutional logics }\end{array}$ & $\begin{array}{l}\text { Disconnects potential collaborators } \\
\text { with different institutional norms and } \\
\text { practices; leads to missed collaboration } \\
\text { opportunities; creates redundancy and } \\
\text { competition }\end{array}$ \\
$\begin{array}{ll}\text { Financial and } \\
\text { human resources } \\
\text { constraints }\end{array}$ & $\begin{array}{l}\text { Limits support for establishing } \\
\text { provision of certain services and } \\
\text { participation in joint efforts; hinders } \\
\text { volunteering }\end{array}$ \\
Geographic & $\begin{array}{l}\text { Obstructs efforts to mobilise potential } \\
\text { collaborators and spread progress } \\
\text { beyond the core communities; upholds } \\
\text { geographic disparities }\end{array}$ \\
\hline
\end{tabular}

All four communities pursued the Blue Zones Project in the early 2010s. The Blue Zones Project was a community improvement initiative, focusing on improving well-being by prompting communities to make environment, policy and social changes to enable healthy choices. In pursuing the Blue Zones certification, the communities developed and implemented health-promoting programmes such as community gardens, safe walking and biking routes and improvement of outdoor environment. More importantly, the initial effort established a cross-sector committee in each of the four communities that served as a communitywide forum for addressing health issues. Although none of the four communities were certified as Blue Zones, the committees continued to play a central role in promoting health and well-being. One community formalised its Blue Zones committee, which became a non-profit organisation and secured grant funding for additional health initiatives. The other three communities used their committees to coordinate further health initiatives developed by different organisations and groups.

Hospital vision: Almost all interviewees stated that the hospital in their community was leading the way on key health and wellness initiatives. This recognition is understandable considering that hospitals are often the largest employer in rural counties and possess resources and expertise to catalyse health programmes. In all four communities, hospital leaders embraced a broad view of health and developed similar visions to be 'the hub for improving health and well-being'. The visions included an expansion of the hospitals' role in each community and prompted hospitals to initiate collaborations with other sectors. Hospital executives indicated that the visions changed the mindsets of hospital leaders and staff, which paved the way to make investment decisions in initiatives that had a positive, long-term impact on community health despite financial burdens on the institution.

Cross-sector leadership and governance: The interviews indicated that not all cross-sector collaborations operated effectively. One differentiating factor was the leadership and governance structure. Our results show that cross-sector partnerships in which a shared leadership and governance structure was established were rare. Most initiatives employed a cross-sector interaction form where one participant took the leadership role with little shared governance structure or shared decision-making. Organisations participating in cross-sector partnerships indicated that shared leadership helped them create common aims and measures among core partners, mutually reinforce activities and reduce redundancy and competition. It was important for fostering communication and trust. One hospital administrator explained that shared leadership helped to engage partners over time. Beyond the perceived benefits, we observed that collaborations with a shared leadership form tended to make more evident impact because they often developed formal evaluation plans to hold all parties accountable.

\section{Challenges inhibiting cross-sector collaborations}

Three inhibiting factors for mobilising cross-sector collaborations in rural communities emerged in our analysis (see table 3).

Different institutional logics: Because potential contributors to cross-sector collaborations come from different sectoral and professional backgrounds, they have developed different norms and practices for framing, prioritising and addressing health issues. These differences inhibited collaborations in two ways. First, organisations with different stakeholders and institutional logics found establishing connections with other sectors challenging. This challenge often manifested as difficulties in coordinating different priorities, performance measures and reporting structures. As a result, organisations were reluctant to cooperate with potential partners from other sectors. This was more evident between key institutional players in healthcare and public health sectors. Second, when one collaborator spearheaded projects and framed them narrowly using sectoral or unilateral narratives, it was often difficult to recruit or engage other collaborators. These issues led to missed collaboration opportunities and sometimes resulted in redundancy and competition in programming. 
Financial and human resources constraints: Financial and human resources constraints often inhibited the creation, operation and sustainment of cross-sector collaborations in rural communities. In all four communities, interviewees discussed the limited funding to support services and programmes, particularly the public health services, which constrained organisations from engaging in collaborations. Moreover, external funding sources such as federal grants were not accessible to most rural communities because of eligibility issues or lack of skilled staff to pursue them. The four communities typically relied on local funding sources such as community foundations, donations and tax dollars to support collaborative initiatives. Furthermore, all four communities had difficulty in recruiting volunteers for some programmes, which undermined their sustainability.

Geographic dispersion: Dispersion of rural populations created unique challenges for spreading gains from collaborative efforts to communities on the edge of geographic boundaries. All four case sites acknowledged that their core communities, which were county seats, benefited the most from health initiatives. Distances between rural towns inhibited communication and interaction between potential collaborators and limited the reach of existing collaborations. Members of the geographically dispersed communities often had increased difficulties accessing the services and programmes offered. The lack of public and private transportation options was a significant barrier for certain populations, such as seniors and people who live in poverty.

\section{Perceived impact}

We identified three themes related to the perceptions of collaborative health initiatives' impact on community, collaborators and culture. First, interviewees observed changes in behaviours and practices within communities as a result of nutrition education or fitness initiatives. For example, interviewees commented on an increased demand from community members for healthy options that eventually changed menus in certain restaurants. Second, collaborators started to see advantages of working together. One commonly discussed collaborative advantage was better coordination, which led to better use of available resources, less duplication and improved programming. Third, collaborative health initiatives were perceived to lead to a gradual improvement in culture. Interviewees described examples of people in their communities valuing health more highly and influencing others to lead healthier lives.

Formal evaluation was rarely used in the four communities to assess the impact of specific initiatives. However, two initiatives, both focusing on physical activities and nutrition for K-12 children, routinely collect data on body mass index (BMI), perceptions of fruits and vegetables and perceptions of physical activities. One initiative' evaluation results showed that students with more initiative exposure had slower BMI growth.

\section{DISCUSSION}

This research contributes an understanding of the context, forms and impact of cross-sector collaborations in rural communities. Our findings highlight several important patterns and factors that policymakers and rural communities need to address to enable effective cross-sector collaborations for improving population health.

First, many organisations from different sectors expressed strong interests and initiated actions towards improving population health. Most of them, however, have not been able to establish real and lasting partnerships to address broader community-wide issues or address issues in a systematic way. Institutional differences and resource constraints may play a role in inhibiting cross-sector partnerships. The lack of practical knowledge or a framework for developing cross-sector partnerships in a rural context is another challenge faced by rural communities. Several participants stressed the importance of shared leadership, governance and decision-making in their collaboration experience. Consistent with recommendations from public administration experts, the timing of shared structure formation is critical. ${ }^{1021}$ Collaborations that are initiated by joint effort and that develop a shared governance structure early will have more opportunities to bring together diverse viewpoints, reconcile institutional differences and develop shared action plans. One possible strategy is to encourage healthcare and public health organisations to collaborate with non-health sectors in conducting community health needs assessment and strategic planning.

Second, culture change is a slow process. Although we cannot pinpoint the origin of this process in the four communities, their experiences suggest that actions taken and the culture experienced by community members can mutually reinforce each other. Both community context and seed initiatives facilitated the development of crosssector collaborations, which in turn strengthened a perception of community and culture of health.

Third, some challenges are magnified by the rural context. Specifically, public health departments are often underfunded, which constrains public health professionals to narrowly defined tasks such as vaccination and emergency preparedness while missing opportunities to lead or participate in initiatives for improving broader population health and well-being. Geographic dispersion of communities in conjunction with a lack of transportation options limits the impact of health initiatives in rural communities and subpopulations. Yet no organisation or systematic approach was identified as appropriate for addressing this challenge. Community development organisations, which play an important role in urban settings to address transportation, housing and other community projects, ${ }^{13}$ were entirely absent in the four rural communities that we studied.

This study extends the existing literature on the increasing use of cross-sector collaborations in addressing social determinants of health and health promotion ${ }^{1142223}$ 
by documenting such practices in rural communities. Our findings highlight rural-specific challenges in implementing cross-sector strategies, which require future research and policy interventions to address. Specifically, a collaborative approach to gathering and applying evidence is crucial to implementing effective cross-sector strategies. ${ }^{24}$ Thus, the development of an evidence base for rural-specific facilitators, challenges and effective strategies is in demand. Further, many conditions inhibiting rural communities from making progress in closing the rural-urban gap in population health outcomes are impracticable to change with local resources and actions. Such conditions require policy attention and resource commitment to improving social determinants of health in the rural context. ${ }^{25}$

Our analysis had several limitations. First, we are limited in our ability to generalise the findings to other rural communities based on only four cases. Local context might significantly influence the types of collaborations and factors contributing to their success. Our findings may not capture the diversity in rural experiences. Second, our data on cross-sector activities were reported by key informants. Although we used snowball sampling to increase the pool of informants, because of recall bias, we may have underreported the number and extensiveness of cross-sector activities in these communities and missed important historical factors that could influence the development of cross-sector collaborations. Third, we focused on rural communities that demonstrated progress towards creating healthy communities to generate knowledge about their experience with crosssector collaborations. We did not include communities lagging in such progress in our study. Thus, we do not know whether rural communities that rank significantly differently on County Health Rankings face different challenges in mobilising cross-sector collaborations to address health issues or they face similar challenges to a different degree.

\section{IMPLICATIONS FOR POLICY AND PRACTICE}

Our research offers several practice and policy implications. For rural communities, initiating local actions and changes is imperative for creating healthier communities. Such actions or seed initiatives have the potential to improve local context and culture with lasting impact. Reconciling institutional differences and developing shared leadership and governance in cross-sector collaborations early helps build partnerships, establish common goals, coordinate resources and actions, engage collaborators over time and achieve collective impact. Defining and measuring outcomes early helps all partners see objectives clearly and thus engage in the collaborative effort in such a way that contributes to goal achievement.

For policymakers, broadening the scope of work of local public health departments and supporting them with funding and staff will strengthen the role of the public health sector and facilitate cross-sector collaborations.
Special investments are needed to attenuate the resource and infrastructure barriers in rural communities. For example, funders from both the government and private sectors should consider designing special funding opportunities to support cross-sector collaborations in rural communities, making information more accessible and providing guidelines or technical support to assist rural communities in pursuing such opportunities. Stakeholders at the local, regional and national levels should consider developing policies and incentives to encourage community development organisations to engage in rural community development projects in order to improve key aspects of the community infrastructure.

\section{CONCLUSION}

This study shows that rural communities use cross-sector collaborations to address community health issues in the forms of interaction and exploration, but real and lasting partnerships are rare. The development, operation and sustainment of cross-sector collaborations are influenced by a set of contextual and practical factors. Practical strategies and policy interventions may be used to enhance cross-sector collaborations in rural communities.

Acknowledgements We thank the interviewees who participated in this research for sharing their knowledge and experiences. We thank Dr Marcia Ward, Dr Thomas Vaughn and Mr Fred Ullrich for contributing to this research and providing feedback on earlier versions of this manuscript.

Contributors XZ and KM designed the study. XZ, MN, NG and KM collected the interview and achieve data. XZ, PW, JB, MN and NG analysed the data and produced the tables. XZ prepared the initial draft of the manuscript. All authors critically revised the manuscript and approved the final version of the manuscript.

Funding This research was supported by funding from the Robert Wood Johnson Foundation (RWJF, Grant number 73062).

Disclaimer The content of this paper is solely the responsibility of the authors and does not necessarily represent the views of RWJF.

Competing interests None declared.

Patient consent for publication Not required.

Provenance and peer review Not commissioned; externally peer reviewed.

Data availability statement Data are available on reasonable request.

Open access This is an open access article distributed in accordance with the Creative Commons Attribution Non Commercial (CC BY-NC 4.0) license, which permits others to distribute, remix, adapt, build upon this work non-commercially, and license their derivative works on different terms, provided the original work is properly cited, appropriate credit is given, any changes made indicated, and the use is non-commercial. See: http://creativecommons.org/licenses/by-nc/4.0/.

\section{REFERENCES}

1 Marmot M, Friel S, Bell R, et al. Closing the gap in a generation: health equity through action on the social determinants of health. The Lancet 2008;372:1661-9.

2 Bircher J, Kuruvilla S. Defining health by addressing individual, social, and environmental determinants: new opportunities for health care and public health. J Public Health Policy 2014;35:363-86.

3 Adler NE, Cutler DM, Jonathan J, et al. Addressing social determinants of health and health disparities. Washington DC: National Academy of Medicine, 2016.

4 Stringhini S, Sabia S, Shipley M, et al. Association of socioeconomic position with health behaviors and mortality. JAMA 2010;303:1159-66.

5 Braveman P, Egerter S, Williams DR. The social determinants of health: coming of age. Annu Rev Public Health 2011;32:381-98. 
6 Galea S, Tracy M, Hoggatt KJ, et al. Estimated deaths attributable to social factors in the United States. Am J Public Health 2011;101:1456-65.

7 Plough AL. Building a culture of health: a critical role for public health services and systems research. Am J Public Health 2015;105 Suppl 2:S150-2.

8 Robert Wood Johnson Foundation. From vision to action: measures to mobilize a culture of health. Princeton, NJ: Robert Wood Johnson Foundation, 2015

9 Chandra A, Acosta JD, Carman K, et al. Building a national culture of health: Background, action framework, measures, and next steps. Santa Monica, CA: RAND Corporation, 2016.

10 Bryson JM, Crosby BC, Stone MM. Designing and Implementing Cross-Sector Collaborations: Needed and Challenging. Public Adm Rev 2015;75:647-63.

11 Johnston LM, Finegood DT, Partnerships C-S. Cross-sector partnerships and public health: challenges and opportunities for addressing obesity and noncommunicable diseases through engagement with the private sector. Annu Rev Public Health 2015;36:255-71.

12 Bryson JM, Crosby BC, Stone MM. The design and implementation of Cross-Sector collaborations: Propositions from the literature. Public Adm Rev 2006;66:44-55.

13 Mattessich PW, Rausch EJ. Cross-Sector collaboration to improve community health: a view of the current landscape. Health Aff 2014:33:1968-74.

14 Braunstein S, Lavizzo-Mourey R. How the health and community development sectors are combining forces to improve health and well-being. Health Aff 2011;30:2042-51.
15 Mays GP, Mamaril CB, Timsina LR. Preventable death rates fell where communities expanded population health activities through multisector networks. Health Aff 2016;35:2005-13.

16 Remington PL, Catlin BB, Gennuso KP. The County health rankings: rationale and methods. Popul Health Metr 2015;13:11.

17 Fetters MD, Curry LA, Creswell JW. Achieving integration in mixed methods designs-principles and practices. Health Serv Res 2013;48:2134-56.

18 USDA. Urban influence codes, 2013. Available: http://www.ers.usda. gov/data-products/urban-influence-codes.aspx [Accessed 12 Aug 2016].

19 Hruschka DJ, Schwartz D, St.John DC, et al. Reliability in coding open-ended data: lessons learned from HIV behavioral research. Field methods 2004;16:307-31.

20 Ryan GW, Bernard HR. Techniques to identify themes. Field methods 2003;15:85-109.

21 Vangen S, Hayes JP, Cornforth C. Governing Cross-Sector, Inter-Organizational collaborations. Public Management Review 2015;17:1237-60.

22 Alley DE, Asomugha CN, Conway PH, et al. Accountable Health Communities--Addressing Social Needs through Medicare and Medicaid. N Engl J Med 2016;374:8-11.

23 de Montigny JG, Desjardins S, Bouchard L. The fundamentals of cross-sector collaboration for social change to promote population health. Glob Health Promot 2019;26:41-50.

24 Armstrong R, Doyle J, Lamb C, et al. Multi-sectoral health promotion and public health: the role of evidence. $J$ Public Health 2006;28:168-72.

25 McGinnis JM, Williams-Russo P, Knickman JR. The case for more active policy attention to health promotion. Health Aff 2002;21:78-93. 